\title{
HEALTH CARE PRIORITY AND RARE MALIGNANT DISEASES: ORPHAN THERAPY IN BRCA 1/2 MUTATED OVARIAN CANCER - EXPERIENCE FROM MONTENEGRO
}

\author{
Nada Cicmil-Sarić1, Sanja Lekić1, Mirjana Branković-Magić ${ }^{2}$, Ana Krivokuća ${ }^{2}$ \\ ${ }^{1}$ Clinic for Oncology and Radiotherapy Clinical Center of Montenegro, Podgorica, Montenegro \\ ${ }^{2}$ Institute for Oncology and Radiology of Serbia, Laboratory for Molecular Genetics ${ }^{2}$, Belgrade, Serbia
}

\section{PRIORITETI U ZDRAVSTVU I RIJETKE MALIGNE BOLESTI: ORFAN TERAPIJA KOD BRCA 1/2 MUTIRANOG RAKA JAJNIKA- ISKUSTVO IZ CRNE GORE}

\author{
Nada Cicmil-Sarić, Sanja Lekić, Mirjana Branković-Magić2 ${ }^{1}$, Ana Krivokuća ${ }^{2}$ \\ 1Klinika za onkologiju i radioterapiju Klinički centar Crne Gore, Podgorica, Crna Gora \\ 2Institut za onkologiju i radiologiju Srbije, Laboratorija za molekularnu genetiku, Beograd, Srbija
}

\begin{abstract}
Ovarian cancer is not the most common, but certainly remains the deadliest of all gynecological tumour. New molecular genetic studies classify ovarian cancer as type 1 and type 2. Subtype 2 of a serous papillary ovarian cancer of high grade is dominant, aggressive and it is the cause of death in 70-80\% of the total number of women. In terms of the therapeutic response, ovarian cancer is divided into platinum-sensitive and platinum-resistant. The latest treatment to maintain the achieved therapeutic response in a relapsed disease, that is platinum responsible and BRCA 1/2 mutated, is the use of PARP inhibitors. EMA has approved the use of a PARP inhibitor as an orphan drug for this indication. Herein, we present two cases and analyze the way in which developing countries, including Montenegro, provide the most modern treatment for these patients.
\end{abstract}

Key words: ovarian neoplasms; tumour suppressor proteins; rare diseases.

\section{INTRODUCTION}

Ovarian cancer is a major public health concern. Though it is not the most common malignant disease in general, and although it is not the most common form of gynecologic malignancy, ovarian cancer is certainly the deadliest of all gynecological tumors. The World Health Organization (WHO) estimates that the number of newly diagnosed diseased women is about 225, 500 a year. About 140,200 patients worldwide die annually of this disease. Ovarian cancer is thus ranked as the seventh in the frequency of carcinomas. It is located in the eighth place as a causative agent for cancer-related deaths. In the countries of Western Europe, it is even ranked fifth (1-3). Overall, these figures indicate ovarian cancer as a significant source of morbidity and mortality in the global population of women. Significant majority, as many as $85 \%$ of ovarian cancer cases are diagnosed late in the advanced stage of the disease. Long discussions focused on the origin of serous ovarian cancer. When it comes to serous high-grade tumors, today's widespread

\section{SAŽETAK}

Rak jajnika nije najčešći, ali izvjesno predstavlja najsmrtonosniji ginekološki tumor. Nove molekularno genetske studije dijele rak jajnika na tip 1 i tip 2. Dominantan je agresivan podtip 2 seroznog papilarnog raka jajnika visokog gradusa, koji u 70-80\% slučajeva prouzrokuje smrtni ishod. U smislu terapijskog odgovora, rak jajnika se dijeli na platina senzitivni i platina rezistentni. Savremeni tretman održavanja postignutog terapijskog odgovora kod rekurentne bolesti, koja odgovara na liječenje derivatima platine a koja je BRCA 1/2 mutirana, jeste primjena PARP inhibitora. EMA je odobrila primjenu jedne vrste PARP inhibitora iz grupe orfan lijekova za ovu indikaciju. Prikazujemo dva slučaja i analiziramo način na koji se u zemljama u razvoju, u koje spade $i$ Crna Gora, obezbjeđuje najsavremeniji tretman za ove pacijentkinje.

Ključne riječi: neoplazme ovarijuma; proteini supresori tumora; rijetke bolesti.

understanding is that most of these neoplasms lead origin from the epithelium of the fallopian tube.

Recent molecular genetic studies of epithelial ovarian cancer have (EOC) led to the introduction of a new classification that differentiates type 1 and type 2 of this disease. This dual model that has brought new light into ovarian carcinogenesis was proposed in 2004 by Kurman and Shih. This proposal was widely accepted, leading to its formalization by WHO 2014. Then, Kurman's and Shih's suggestions were recognized by the WHO in the supplemented classification of the gynecological tract tumors $(4,5)$. With this model, the wide, heterogeneous EOC group is divided into two broad categories, two types of disease called: type 1 and type 2 . Type 2 is characterized as a pattern with much more aggressive behavior. This tumor group is characterized by rapid growth, frequent metastasis, even at initial presentation of the disease, resulting in poor prognosis and poor outcome of the disease (6). The genetic map of these tumors shows p53 mutations and genomic instability due to the damage 
to pathways that contribute to the repair of DNA (6). It is precisely type 2 high grade serous papillary ovarian cancer that is predominantly a form of clinically diagnosed ovarian cancer and is the cause of death in $70-80 \%$ of women affected by this neoplasm $(6,7)$. In fact, the term ovarian cancer, encompasses a large number of different illnesses that share the same place as their presentations. Even under conditions of optimally performed surgery and appropriately administered adjuvant chemotherapy, a huge percentage of around $70-80 \%$ of ovarian cancer cases relapses. Whether it is about the treatment of ovarian cancer in a neoadjuvant, adjuvant ormetastatic setting, platinum salts remain the cornerstone of treating this disease. The original definition for "platinum sensitivity" was formulated for the secondline of chemotherapy. Today, it relates to lines of therapy that follow one after the other, usually at least three of them being applied to relapsed diseases. Median survival of patients with recurrent ovarian cancer ranges from 12-24 months.

The most important clinical division of recurrent ovarian cancer divides the disease in two groups: "platinum-sensitive" and "platinum-resistant". This classification was made in relation to the length of time since the completion of chemotherapy comprising a platinum agent (carboplatin or cisplatin), up to the time of relapse. Therefore, the platinum-free interval is longer, the longer response time to the applied retreatment is expected. Recurrent ovarian cancer (potential platinumsensitive), 6-12 months sensible and > 12 months sensitive, is defined as the recurrence of active disease in the patient who has achieved a documented response to the initial platinum-based treatment and has been off therapy for an extended period of time. Resistant ovarian cancer, 1-6 months, is defined as a disease that has responded to initial, but demonstrates recurrence within a relatively short period of time following the completion of treatment. Persistent ovarian cancer is the finding of residual disease in a patient who has completed, and apparently responded to initial chemotherapy. Refractory ovarian cancer, up to one month, occurs in patients who have failed to achieve at least a partial response to therapy (8).

It is a long way from the adjuvant application of chemotherapy, neo-adjuvant set-up, and the use of therapy in the metastatic stage of the disease to the therapy to maintain the results achieved by previous treatment. Maintenance therapy in an oncology community dealing with the treatment of solid malignant tumors has always been desirable, and more recently, with new, targeted, personalized medications, maintenance therapy has become a realistic strategy even for recurrent, BRCA 1/2 positive ovarian cancer. BRCA $1 / 2$ positive ovarian cancer is one of the rare diseases (9). Orphanet is a database containing information on rare diseases, which includes a directory of patients' organizations registered in Europe.
On June 18, 2019 the European Commission (EC) has approved olaparib as a 1st-line maintenance treatment for women with BRCA-mutated advanced ovarian cancer, the only one PARP inhibitor in this indication (10). In a previously completed SOLO 2 study, olaparib showed a $70 \%$ reduction in the risk of disease progression, i.e., a prolongation of PFS by almost 14 months relative to placebo, in patients with ovarian cancer relapse and the presence of BRCA mutation, in which olaparib was administered as maintenance therapy after platinum-based chemotherapy. Extending the disease-free progression period allows platinum-sensitivity to be maintained, which is significant for the further course of disease and for the final outcome.

\section{CLINICAL EXPERIENCE}

In June 2017. following a joint meeting and agreement, a contract was signed between the pharmaceutical industry producing a PARP inhibitor approved for ovarian cancer maintenance treatment and the Montenegrin Health Fund. This enabled BRCA $1 / 2$ testing of selected patients at the Oncological Institute of Serbia in the Laboratory for Molecular Genetics. The pharmaceutical industry provided special tubes for serum samples for the analysis of germlineBRCA 1/2 mutations. A blood sample could remain stable in the tubes for up to 14 days. The pharmacologist made it possible to refer biological material using DHL. A special form was created with administrative data filled in by a physician referring to the test sample.

The documentation to be enclosed was: filled out form for BRCA test and report of oncological multidisciplinary team for gynecological cancer. Article 4 of the Law on Health Care Protection of Montenegro refers to rare diseases: "Drugs for rare diseases, although not on a positive list of medicines, have been reimbursed by the Health Fund."

The test criteria were the following:

1. Serous papillary ovarian cancer of high histological grade;

2. Platinum-sensitive disease with no signs of disease at least six months after completion of treatment based on platinum derivatives;

3. At least once relapsed illness;

4. Radiological, serological and clinically established therapeutic benefit after the use of platinum-based therapy in the treatment of relapsing disease.

Time to results issue was 6-8 weeks. Maintenance therapy with the PARP inhibitor should be introduced within 8 weeks after the last cycle of chemotherapy with platinum salts. In the period from $4 / 1 / 2018$ to $14 / 3 / 2019$ we referred to testing samples for a total of six women 
who met these criteria. The response time, i.e. the test results, ranged from 11 to 39 days. The coding sequences of BRCA1 and BRCA2 and exon/intron boundaries were enriched using Nextera DNA Library Preparation Kit in combination with Tru-Sight ${ }^{\circledR}$ Cancer Panel (Illumina, San Diego, USA). Next generation sequencing (NGS) was performed on Illumina MiSeq Sequencing System (Illumina) according to the manufacturer's protocol. Secondary data analysis and base calling were performed by MiSeq Reporter Software 2.5 (Illumina). VCF v4.1 files generated during secondary analysis of sequencing data were imported into Illumina Variant Studio software for variant annotation and filtering.

Two results were positive for the presence of class 5 deleterious mutations: one in BRCA $1 / 2$ gen and another BRCAness in MSH2 gene.The MSH2 gene is associated with the occurrence of BRCAness meaning that it belongs to the category of genes whose mutations can contribute to the response to targeted therapy with PARP inhibitors (11). In particular, expanded applications of PARP inhibitors are anticipated following recent reports that defects in homologous recombination repair (HRR) are associated with mutations in repair genes other than BRCA1/BRCA2, such as ATM, ATR, PALB2, RAD51, CHEK1 and CHEK2, as well as with epigenetic loss of BRCA1 function through promoter methylation or overexpression of the BRCA2-interacting transcriptional repressor EMSY $(12,13)$.

We obtained the test results as oncologist in charge, from colleagues at the Laboratory for Molecular Genetics in Serbia via e-mail. Histopathological tissue analysis was performed at the Center for Pathology of the Clinical Center of Montenegro. In both patients, the primary histopathological diagnosis was made according to the previous WHO histopathological classification of ovarian cancer.

Relapse of disease in both women occurred in 2018, so the tissue analysis and the diagnosis were in line with the new WHO pathological classification published in 2014. by Robert Kurman and co-authors. Both patients met all four criteria required for referral to BRCA testing. The first patient, aged 57 years, was radically surgically treated: total classical hysterectomy with bilateral adnexectomy and omentectomy. The other patient, aged 42 years, is familiar with the risk of partial surgery, unilateral adnexactomy, but expressed the desire to preserve the potential for birth. She signed the agreement, so a partial intervention was made: one-sided adnexactomy. The patients received six cycles of paclitaxel and carboplatin combinations in the adjuvant set. The period without signs of disease in the first patient lasted for 45 months, meaning that the disease was sensitive to the use of platinum salt. DFS of 7 months in another patient means that the disease was sensible to platinum. Relapse disease in inguinal lymph nodes has been confirmed clinically, serologically (CA125; HE4), radiological digital imaging (US, MSCT) and PET CT in one patient. Disease relapse in contralateral adnexas in other patient was established by clinical, digital radiological imaging (US; MSCT; MRI) and serological analysis (CA125; HE4).

In both patients, the relapses were surgically treated: one of them had inguinal lymphadenectomy, while in the other the uterus, remaining ovary and omentum were removed. Treatment of the first patient was continued with six chemotherapy cycles: paclitaxel + CBDCA and another patient received six cycles of mono chemotherapy, CBDCA. After the application of three chemotherapy cycles, elevated serum tumor markers were normalized in both women. ECOG for both patients was 0. After completing all six chemotherapy cycles, we performed the re-evaluation: MSCT chest, abdomen, gynecological examination and ultrasound, MRI of the pelvis, blood count analysis, biochemical analysis and analysis of serum tumor markers: CA125, HE4 and ROMA index.

The results of the examinations and analyzes were normal. A serum sample for 22 mutations was taken and referred to analysis at the Molecular Genetics Laboratory at the Oncological Institute in Belgrade after three chemotherapy cycles had been applied. The results of the analysis were obtained in the first patient after 18 and in the second after 11 days. The result of the analysis in the first patient: a pathogenic class 5 mutation in the BRCA 1/2 gene was detected. Result in the other patient: a pathogenic class 5 mutation in the MSH2 gene was detected. The oncologist made a medical report with a suggestion for the use of PARP inhibitors in maintenance therapy.

The report was sent to the multidisciplinary team for gynecological cancer tumors. The opinion of the multidisciplinary team was positive and was forwarded to the Montenegrin Ministry of Health Commission for making the final decision as the PARP inhibitor was not on the positive list of medicines of the Montenegrin Health Fund. In accordance with Article 4 of the Health Insurance Act of Montenegro, which reimburses the costs for medicines intended for the treatment of rare diseases, both patients were granted approval for the use of PARP inhibitors in maintenance therapy. Treatments started within the scheduled timeframe: eight weeks after the last cycle of chemotherapy. The first patient was six and a half months in maintenance therapy until mid-July 2019 and the other on that date was the PARP inhibitor taking two months with excellent objective and subjective tolerance.

\section{DISCUSSION}

New era has made great progress, but also a challenge in the treatment of malignant diseases. In the field of melanoma therapy, ovarian cancer, even NSCLC and 
breast cancer, we are witnesses to the chronic course of these diseases due to the use of modern medications.

Every scientific research in medicine and pharmacy has, as its most important goal, the safe and successful use of modern medicines for those for whom these are intended and by whom they are needed. The studies lasted for a number of years and had great financial investment as well as engaging in a number of other resources.

Expensive, long-lasting clinical trials that result in high prices of oncological drugs often make these new molecules unavailable to patients in developing countries. According to the last the population consensus made in 2011, Montenegro had 620029 inhabitants. Montenegro does not own the National Cancer Registry. The oncology and radiotherapy clinic in the city, Podgorica, is a tertiary health care institution. Oncologic diagnosis and treatment are performed by two other institutions: the Center for Hematology in Podgorica and the Brezovik Special Hospital in Niksic. Presentation and treatment of the vast majority of malignant diseases in Montenegro is gravitated by the Oncology and Radiotherapy Clinic in Podgorica. Since 2013, the clinic has a Microsoft program for writing and keeping expert decisions made by multidisciplinary teams. Developing countries, including Montenegro, with an average investment of the 329E in the Montenegrin health fund, are faced with an additional significant problem: inadequate financial resources for the purchase of expensive medicines. The situation is more complex, and the positive list of medications is rarely upgraded: it sometimes goes on for years until this happens. Also, additional health insurance and private investment in insurance, in Montenegro, are still not a living practice. The obstacle is also molecular genetic testing, which is expensive and works only in some reference centers. There are various ways in which treatment can be provided for the patient: special confidential contracts between state health authorities and pharmaceutical companies, compassionate use programs, inclusion of patients in clinical studies, etc. Montenegro, as a country with a small population, is almost never able to be involved in wider clinical studies, and is rarely involved in compassionate use and similar programs. Ovarian cancer is not among the most common malignancies, nor is the most common malignant gynecological disease in women: on the other hand, it represents the most deadly form of gynecological tumor.

An additional problem lies in the fact that ovarian cancer is not a group of preventive malignant tumors. In light of these circumstances, adequate therapy remains the only option for as effective as possible treatment of the patients. The database data of the National Institute for Public Health records 2784 new cases of malignant neoplasm registered in Montenegro in 2013. (out of which, 325 cases were non-melanoma malignant tumors of the skin). Of these, $47 \%$ of newly diagnosed patients are women. Of the ovarian cancer, 51 women were affected. There were 34 deaths from ovarian cancer. The ovarian cancer accounts for $4.3 \%$ of all malignant gynecological diseases in Montenegro. The largest number of patients belongs to the age group of 60 years (15). Montenegro does not have its own therapeutic defined protocols and guides for diagnosis and treatment of malignant diseases. We apply and refer to ESMO / NICE / NCCN guides. In this context, Montenegro has practically all pharmacies for the treatment of relapsing ovarian cancer. We use: paclitaxel, CBDCA, CDDP, gemcitabine, bevacizumab, vepeside with pronison, ADR, cyclophosphamide, navelbine and topotecan. We do not have the possibility of using liposomal anthracyclines.

Knowledge, desire and commitment of health professionals to help the patient and to provide him with the maximum opportunities for adequate treatment, represent the greatest inspiration for all available resources to be pursued in pursuit of this goal. All subjects: from medical practice, state-run institutions, pharmaceutical industry and patient organizations themselves must be involved and active. PARP inhibitors and anti VGF agencies have taken up their place when it comes to maintenance therapy for ovarian cancer (16). Maintaining the sensitivity of tumors to platinum derivatives for as long as possible is crucial to the final outcome and success of therapy $(17,18)$. Maintenance therapy was a great challenge for both: oncologists and patients suffering from relapsing ovarian cancer in Montenegro.

Herein we have analyzed and presented two cases of successful realization of this kind of cooperation for the benefit of the patient. A successful outcome is based on good regional co-operation. We appealed to Article 4 of the Montenegrin Health Insurance Act, which deals with rare malignant diseases. A successful outcome confirmed the accuracy of the principles of rare diseases: "Alone, we are rare, together we are strong." We list the words of Lynne Eldridge, MD, who says: "Add all rare cancers together and they are quite common. In this current area, finding treatments for rare cancers is not only important ethically, but benefits people with all cancers.".Given that there are variations in the percentage of ovarian cancer of high histological grade and serous papillary cancer of high histological grade, the percentage of tumors carrying BRCA $1 / 2$ mutations may be different (19-22). BRCA $1 / 2$ mutated ovarian cancer is a rare disease (10). Adequate therapy for this group of patients is the PARP inhibitor, which is the only currently registered orphan-setting drug for maintenance of BRCA $1 / 2$ positive ovarian cancer (9). By looking at absolute numbers, the figure of two patients BRCA $1 / 2$ or BRCA ness carriers may look low (15). Bearing in mind that the probability of detecting BRCA 
$1 / 2$ positive ovarian cancers ranges from 4 to $9 \%$ of newly diagnosed cases at annual level, this means that 2-4 women in Montenegro were potentially indicated for PARP inhibitor treatment. In this framework, the patient selection we made and the results of our work can be considered as professional, socially responsible, financially predictable and successful. We need to maintain this result and further improve it. This in particular implies that in addition to germline testing, somatic mutation testing should be introduced.

In conclusion, scientific foundations, dedication, persistence, and good co-operation with a large number of subjects, are an indispensable prerequisite for providing optimal treatment for patients with many malignancies including BRCA 1/2 mutated ovarian cancer in developing countries. Cooperation involves the patient, oncologist in charge, multidisciplinary oncology team, state health care organization, pharmaceutical industry, molecular genetics centers. Teamwork must be consistent, continuous, timely, based on internal and regional co-operation. Patient selection must be of high quality, which guarantees professional justification, social responsibility and financial predictability as the ultimate result. We also have the opportunity to apply the latest knowledge such as the following: in particular, expanded applications of PARP inhibitors are anticipated following recent reports that defects in homologous recombination repair (HRR) are associated with mutations in repair genes other than BRCA1/BRCA2. There are no associations in Montenegro for the rights of patients suffering from malignant diseases. This "missing link" should, as soon as possible, become a very important continuous help for oncology professionals.

\section{ABBREVIATIONS}

ATM: a gene, serine/threonine protein kinase

ATR: a gene, serine/threonine-protein kinase also known as ataxia telangiectasia and Rad3-related protein (ATR) or FRAP-related protein 1 (FRP1)

BRCA1,2: BReastCAncer

CBDCA: the carboplatin

CA125: cancer antigen 125 , mucin 16 or MUC16 protein DFS: disease free survival

DHL: international shipping, courier, and packaging service. DHL was established in 1969 by Adrian Dalsey, Larry Hillblom, and Robert Lynn. The name DHL is derived from the first initial of each founder's last name

DNA: Deoxyribonucleic Acid

EC: European Comission

ECOG: EasternCooperativeOncologyGroup
EMSY: a gene, EMSY, BRCA2 interacting transcriptional repressor

EOC: epithelial ovarian cancer

HE4: human epididymis protein 4

HGSOC: High Grade Serous Ovarian Cancer

HRR: homologous recombination repair

MESH1: a gene, Guanosine-3',5'-bis(diphosphate) 3'pyrophosphohydrolase

MESH 2: a tumor suppressor gene and more specifically a caretaker gene that codes for a DNA mismatch repair (MMR) protein

MRI: the magnetic resonance imaging

MSCT: the multislice scanner tomography

NGS: New Gene Sequencing

PALB2: Partner And Localizer of BRCA2, also known as PALB2 or FANCN, a protein which in humans is encoded by the PALB2 gene

PARP: Poly-ADP Ribose Polymerase

PET CT: the positron emission tomography scanner tomography

RAD 51: the bacterial recA gene and its eukaryotic homolog RAD51, important for

DNA repair, homologous recombination

ROMA index: Risk of Ovarian Maligancy Algorithm

SOLO 2: the trial designed to determine the efficacy of olaparib) tablets as a monotherapy for the maintenance treatment of platinum-sensitive relapsed, BRCAmutated ovarian cancer

US: the ultrasound

WHO: World Health Organisation

\section{REFERENCES}

1. Lisio MA, Fu L, Goyeneche A, Gao ZH, Telleria C. High-grade serous ovarian cancer: basic sciences, clinical and therapeutic standpoints. Int $\mathrm{J}$ Mol Sci 2019; 20(4). pii: E952. (doi: 10.3390/ijms20040952).

2. Jemal A, Bray F, Center MM, Ferlay J, Ward E, Forman D. Global cancer statistics. CA Cancer J Clin 2011; 61: 69-90.

3. Ferlay J, Soerjomataram I, Dikshit R, et al. Cancer incidence and mortality worldwide: sources, methods and major patterns in GLOBOCAN 2012. Int J Cancer 2015; 136: E359-E386.

4. Kurman, RJ, Carcangiu ML, Herrington CS, Young RH. WHO Classification of tumours of female reproductive organs. 4th ed. Geneva: World Health Organization, 2014.

5. Shih IE, M, Kurman RJ. Ovarian tumorigenesis: a proposed model based on morphological and molecular genetic analysis. Am J Pathol 2004; 164: 1511-8. 
6. Lengyel, E. Ovarian cancer development and metastasis. Am J Pathol 2010; 177; 1053-64.

7. Bowtell DD, Böhm S, Ahmed AA. etal. Rethinking ovarian cancer II: reducing mortality from high-grade serous ovarian cancer. Nat Rev Cancer 2015; 15: 668-79.

8. Luvero D, Milani A, Lederman JA. Treatment options in recurrent ovarian cancer: latest evidence and clinical potential. Ther Adv Med Oncol 2014; 6: 229-39.

9. EURORDIS Rare Diseases Europe. Paris, Brussels, Barcelona: EURORDIS-Rare Diseases Europe, 2019. (https://www.eurordis.org/).

10. Public summary of opinion on orphan designation. Olaparib for the treatment of ovarian cancer. London: European Medicines Agency, Committee for Orphan Medicinal Products, 2015. EMA/COMP/510787/2007 Rev.3.

(https://www.ema.europa.eu/en/documents/orphandesignation/eu/3/07/501-public-summary-positiveopinion-orphan-designation-olaparib-treatmentovarian-cancer_en.pdf).

11. Fleury H, Carmona E, Morin VG, et al. Cumulative defects in DNA repair pathways drive the PARP inhibitor response in high-grade serous epithelial ovarian cancer cell lines. Oncotarget 2017; 8: 40152-68.

12. Ohmoto A, Yachida S. Current status of poly (ADPribose) polymerase inhibitors and future directions. Onco Targets Ther 2017; 10: 5195-8. (doi: 10.2147/OTT.S139336).

13. Bitler BG, Watson ZL, Wheeler LJ, Behbakht K. PARP inhibitors: clinical utility and possibilities of overcoming resistance. Gynecol Oncol 2017; 147: 695-704.

14. Meinhold-Heerlein I, Fotopoulou C, Harter P, et al. The new WHO classification of ovarian, fallopian tube, and primary peritoneal cancer and its clinical implications. Arch Gynecol Obstet 2016; 293: 695700 .
15. Malignant neoplasms in Montenegro 2013. Podgorica: Insitute of Public Health of Montenegro, Center for Control and Prevention of Non-communicable Diseases, Registry of Malignant Neoplasms of Montenegro, 2018.

16. Ovarian Epithelial, Fallopian Tube, and Primary Peritoneal Cancer Treatment (PDQ $\left.{ }^{\circledR}\right)-$ Health Professional Version. Bethesda: National Cancer Institute, 2019.

(https://www.cancer.gov/types/ovarian/hp/ovarianepithelial-treatment-pdq).

17. Schrader KA, Hurlburt J, Kalloger SE, et al. Germline BRCA1 and BRCA2 mutations in ovarian cancer: utility of a histology-based referral strategy. Obstet Gynecol 2012; 120(2 Pt 1): 235-40.

18. Friedlander M, Trimble E, Tinker A, Alberts D, et al.Gynecologic Cancer InterGroup. Clinical trials in recurrent ovarian cancer. Int J Gynecol Cancer 2011; 21: 771-5.

19. Alsop K, Fereday S, Meldrum C, et al. BRCA mutation frequency and patterns of treatment response in brca mutation-positive women with ovarian cancer: a report from the Australian Ovarian Cancer Study Group. J Clin Oncol 2012; 30: 2654-63.

20. TCGA The Cancer Genome Atlas Network. Comprehensive molecular portraits of human breast tumors. Nature 2012; 490: 61-70.

21. Burgess M, Puhalla S. BRCA 1/2-mutation related and sporadic breast and ovarian cancers: more alike than different. Front Oncol 2014; 4: 19. (doi: 10.3389/fonc.2014.00019).

22. Prat J. New insights into ovarian cancer pathology. Ann Oncol 2012; 23(Suppl 10): x111-7. 